\title{
Laparoscopic Ovarian Drilling
}

Saad A K Amer, FRCOG, MSc., MD

Associate Professor in Gynaecology

Nottingham University, The medical School

Royal Derby Hospital

Uttoxeter Road, Derby DE22 3NE

Email: saad.amer@nottingham.ac.uk

Tel: 01332340131

Fax: 01332785566 


\section{Contents}

Introduction

Historical perspective

Current role of laparoscopic treatment in PCOS

Techniques

Endocrine effects

Clinical outcome

Laparoscopic ovarian drilling and ART

Mechanism of action of LOD

Predictors of the outcome of LOD

Complications

Failure of LOD

Conclusion

References 


\section{Introduction}

Polycystic ovarian syndrome (PCOS) is a very common ovarian endocrinopathy affecting $6-8 \%$ of women of reproductive age and is a major cause of anovulatory infertility accounting for $\sim 75 \%$ of cases [1-4]. According to the 2003 revised ESHRE/ASRM Rotterdam consensus, PCOS is defined as a syndrome of ovarian dysfunction along with the cardinal features of hyperandrogenism and polycystic ovarian morphology. At least two of these three features are necessary for the diagnosis of the syndrome [5]. Another important feature of PCOS is its association with insulin resistance and compensatory hyperinsulinaemia [5]. More recent research reported a prevalence rate of PCOS as high as $20 \%$ based on the 2003 revised Rotterdam diagnostic criteria [6,7].

In PCOS women presenting with anovulatory infertility, clomiphene citrate (CC) is the standard first line treatment for induction of ovulation. According to the Thessaloniki PCOS Consensus on infertility treatment related to PCOS, patients who fail to ovulate/conceive on CC can be offered laparoscopic ovarian drilling (LOD) or gonadotrophin ovarian stimulation [8]. LOD offers several advantages over gonadotrophin therapy and is therefore recommended by many Reproductive Specialists as the preferred second line treatment for ovulation induction after CC.

This chapter will present an overview of the current role of LOD in the management of women with anovulatory PCOS, its techniques, clinical outcomes, possible mechanisms of action, complications and predictors of success.

\section{Historical perspective}

In the 1930s, Stein and Leventhal introduced ovarian wedge resection (OWR) as the first ovulation induction method in women with anovulatory PCOS [9]. Three decades later (in the sixties), when clomiphene citrate (CC) was introduced as an effective ovulation 
induction agent, OWR was largely abandoned due to its associated morbidity [10]. Clomiphene citrate became the standard treatment for anovulatory PCOS and OWR was only rarely resorted to after CC failure [11]. In the late sixties, with the development of operative laparoscopy, there was a renewed interest in ovarian surgery carried out laparoscopically. In 1967, Palmer and de Brux in Franc were the first to describe laparoscopic ovarian biopsies for PCOS achieving encouraging results [12]. In 1984, Gjonnaess was the first to describe ovarian diathermy, which involved making a number of craters on the ovarian surface using the tips of laparoscopic scissors or graspers [13]. This was later modified by Armar and co-workers who punctured the ovary at a number of points using needle diathermy, a technique now called "ovarian drilling" [14]. In 1988, Huber and Co-workers described ovarian drilling using laser energy [15]. The history of LOD is summarised in Table 1.

\section{The current role of laparoscopic ovarian diathermy in PCOS}

According to the Thessaloniki PCOS Consensus on infertility treatment related to PCOS, all overweight and obese PCOS women should first be encouraged to loose weight through life style measures before any medical treatment [8]. Whilst CC remains the standard first-line treatment in anovulatory PCOS women, the second line treatment has been the subject of much debate, with competition between LOD, gonadotrophin and metformin to be the preferred choice (Fig 1). Perhaps, with the increasing awareness of the predictors of success/failure of each of these treatments, it may now be possible to apply an individually tailored treatment according to each patient's pre-treatment characteristics e.g. metformin may be the treatment of choice for overweight/obese women. However, emerging evidence from large RCTs on metformin does not support its routine use for ovulation induction in PCOS $[16,17]$. On the other hand, LOD and gonadotrophins have been shown to be equally effective in inducing ovulation and producing high pregnancy and livebirth rates in women 
with PCOS (Table $2 \& 3$ ) $[18,19]$. LOD has been recommended by many authors as the preferred choice after CC-resistance/failure as it offers several advantages over gonadotrophins (Table 4). Importantly, in contrast to gonadotrophin therapy, LOD results in mono-ovulation, with no risk of ovarian hyperstimulation syndrome (OHSS) and with an incidence of multiple pregnancies no higher than background rates. Moreover, LOD is less costly and does not require complex monitoring. In an economic evaluation of LOD versus gonadotrophin therapy, Farquhar and co workers estimated the cost per term pregnancy to be $€ 14,489$ for gonadotrophin and $€ 11,301$ for LOD (22\% lower) [20]. Furthermore, a recent long-term economic study by Nahuis and co-workers reported significantly lower costs per live birth after LOD compared to gonadotrophins therapy in CC-resistant PCOS women [21]. In addition, with LOD, a single treatment leads to repeated physiological ovulatory cycles and potentially repeated pregnancies without the need for repeated courses of medical treatment. The main drawback of LOD is the need for general anaesthetic and surgery. Other complications, such as iatrogenic adhesion formation and premature ovarian failure are rare and appear to be of little clinical significance. Advantages and disadvantages of LOD are summarised in Table 4.

We have recently conducted a randomised controlled trial investigating the potential role of LOD as a first line treatment in preference to CC for anovulatory PCOS [22]. Although, the success rates were not significantly different between LOD and CC, there was a trend towards a higher pregnancy rate with $\mathrm{CC}$ treatment. Furthermore, the study provided evidence that LOD is more effective in CC-resistant PCOS patients compared to CC responsive patients. It was therefore concluded that LOD should remain as a second line treatment for anovulatory PCOS. 


\section{Techniques of laparoscopic ovarian drilling}

Numerous techniques of laparoscopic ovarian surgery to induce ovulation in PCOS women have been developed over the years. Most of the techniques involve either taking ovarian biopsies or making multiple punctures on the surface of the ovary using electrocautery or laser. More recently, there have been several attempts to use a transvaginal route to perform the ovarian surgery utilizing either a fertiloscopy or an ultrasound guided approach. Currently, the most widely used technique for ovarian surgery is laparoscopic ovarian drilling (LOD) using electrocautery due to its simplicity, effectiveness, relative safety and low cost. This technique will be described in details in this chapter.

\section{LOD using electrocautery}

Three-Puncture laparoscopy is established and the pelvis is thoroughly inspected for any pathology and the ovaries examined for the features of PCO. The utero-ovarian ligament is grasped with a pair of atraumatic grasping forceps and the ovary is lifted up and stabilized in position away from the bowel (Fig 2a). This is essential to avoid direct or indirect thermal injury to the bowel. A laparoscopic monopolar diathermy needle is used to penetrate the ovarian capsule at a number of points. The active distal part of the needle should measure $7-8 \mathrm{~mm}$ in length and $2 \mathrm{~mm}$ in diameter and project from an insulated solid cone with a wider diameter. When the needle penetrates the capsule of the ovary, the insulated cone controls the depth of penetration and minimizes thermal damage to the ovarian surface. The needle should be applied to the anti-mesenteric surface of the ovary at right angle to avoid slippage and to minimize surface damage (Fig 2a). The site of application should be away from the ovarian hilum and the fallopian tube. This is necessary to avoid damage of the hilum (which can lead to ovarian atrophy) and the fallopian tube (which can cause mechanical infertility). After insertion of the needle through the ovarian capsule, monopolar coagulation electricity current is activated for 5 seconds with a power 
setting of 30w (Fig 2b). Electricity should not be activated before penetrating the surface of the ovary to avoid arcing and to minimize the damage to the ovarian surface due to the charring effect, which may later cause adhesion formation. However, it may be necessary to facilitate the needle insertion by a short burst of diathermy. The ovary is then cooled down by irrigation using Hartmann's solution before releasing it to its normal position. The techniques are summarized in Table 5.

\section{How much energy should be used for LOD?}

The amount of thermal energy used and number of punctures made in each ovary varied considerably in different studies. Between 3 and 25 punctures have been reported with power settings between 30 and 400w [13,23-25]. In a retrospective review of 161 women who underwent LOD, we found that two punctures resulted in poor outcome and three punctures (450 joules/ovary) seemed to represent a plateau dose, above which no further improvement of the outcome was observed. Seven or more punctures seemed to be associated with reduction of the ovarian reserve suggesting excessive ovarian destruction [25]. In a prospective dose finding study utilizing an "up-and-down design" and involving 30 women with anovulatory PCOS undergoing LOD, we have found four punctures (600 joules) per ovary at $30 \mathrm{w}$ for $5 \mathrm{sec}(150$ joules $)$ per puncture to represent the optimum number required to achieve the best result [26].

\section{Depth of needle insertion into the ovary}

It has now been established that deep insertion of the needle into the ovarian stroma during LOD is necessary to achieve optimal results with the lowest amount of thermal energy. The rational for this approach is that deep penetration allows the direct delivery of thermal energy into to the ovarian stroma resulting in more effective destruction of the androgen producing tissue. This effect is thought to be the main mechanism of action of LOD. Deep 
penetration also helps to avoid ovarian surface charring, which is a cause of postoperative adhesion formation. The theoretical benefits of deep needle insertion has been supported by previous research by our group as well as others, which showed that a needle insertion of about $8 \mathrm{~mm}$ into ovarian stroma resulted in good clinical outcomes with a relatively small amount of energy [14,25-26]. On the other hand, Gjonnaess who made shallow craters of 2$4 \mathrm{~mm}$ depth on the ovarian surface, delivered a very high amount of thermal energy (>3750 joules/ovary) to achieve successful outcomes [13].

\section{Other techniques of ovarian electrocautery}

Several authors applied the techniques described by Gjonnaess making craters on the ovarian surface using biopsy or sterilization forceps pressed against ovarian surface for 2-4 seconds delivering monopolar current (200-300w) [13,24,27-29]. Pelosi and Pelosi used monopolar diathermy needle to create 4-6 linear incisions into the ovarian tissue to a depth of 5-7 $\mathrm{mm}$, extending from one end of the ovary to the other along the axis [30]. Merchant used low-watt $(25 \mathrm{w})$ bipolar current to penetrate the ovarian capsule and coagulate all the visible cysts [31]. The overall results of these techniques are comparable and encouraging.

\section{Laser ovarian surgery}

Four lasers have been used including Nd:YAG, CO2, argon and KTP. Nd:YAG laser is delivered via a fine quartz fibre and can be used in the contact and non-contact mode. In the non-contact mode, the laser fibre is applied at a distance of 5-10 mm of the anti-mesenteric surface of the ovary with a power setting of $30-100 \mathrm{w}$. It has been used to make incisions [15] or punctures [32] or to coagulate a wedge-like area [33]. In the contact mode, with a sapphire tip screwed on the flexible laser fibre, the probe can be introduced into the ovarian capsule to create punctures [34] or to cut out a wedge-shaped portion $(0.5 \mathrm{~cm})$ of the ovary [35] CO2 laser has been used to drill 10-40 craters in the ovarian tissue and to vaporize the visible subcapsular follicles. With power setting of $10-30 \mathrm{w}$ in a continuous mode, the laser 
beam is focused to a spot size of $0.2 \mathrm{~mm}$ for 5-10sec per puncture. Argon and Potassiumtitanyl-phosphate (KTP) lasers are delivered by flexible fibres, which are used in the contact mode without special tips. With a power setting of 6-16w all the visible subcapsular cysts can be vaporized and 20-40 punctures can be made in each ovary (Figure 3 ).

\section{Laser versus Electrocautery}

It appears that electrocautery is superior to laser for LOD for a number of reasons. Firstly, electrocautery is more effective than laser in achieving ovulation and pregnancy [32,36,37]. Secondly, laser, especially CO2 laser, may be associated with a higher risk of adhesion formation because it produces more surface injury than electrocautery. Thirdly, electrocautery is less costly and easier to set up. In addition, the effect of diathermy may last longer than the laser effect [37]

\section{Transvaginal ovarian surgery}

In search for less invasive ovarian surgery for PCOS, some authors have described transvaginal approach to apply diathermy, laser or hydrocoagulation to the ovarian stroma. Other authors used transvaginal mini-laparoscopy (fertiloscopy) to perform ovarian drilling. Mio and co-workers were the first to report on the efficacy of transvaginal ultrasound (TVS) guided follicular aspiration in women with PCOS [38]. Syritsa performed TVSguided ovarian drilling using a specially designed monopolar needle, which has a polyester coating except the 2-mm tip [39]. More recently, Zhu and co-workers described TVSguided ovarian interstitial YAG-laser-coagulation [40]. They introduced the YAG fibre through an egg-pickup needle (used for in-vitro fertilization [IVF]) into the ovarian substance under sedation to coagulate 3-5 points. Fernandez and co-workers described the use fertiloscopy to perform ovarian drilling [41]. Ramzy and co-workers injected warm saline (75oC) into the ovarian stroma using IVF pickup needle under TVS-guidance [42]. These early reports have shown encouraging results, although the efficacy and safety of 
these new techniques need to be adequately assessed before they can be recommended for clinical use. The main concern of any transvaginal approach applying any form of energy e.g. electrocautery or laser, is the risk of causing thermal injury to adjacent organs such as the bowel. Two severe adverse events have been reported following fertiloscopic ovarian drilling [43].

\section{Endocrine effects of LOD}

\section{Immediate Effects}

After LOD the main hormonal changes include a rapid and persistent fall of androgens (testosterone $\&$ androstenedione) with a transient increase of gonadotrophins (LH and FSH) during the first $24-48$ hours followed later by a gradual fall $[26,24,44-48]$. Preliminary data suggest that insulin sensitivity and lipoprotein abnormalities associated with PCOS are not improved by LOD [28]. In a previous study involving 50 women with anovulatory PCOS, we reported that serum inhibin B concentrations did not change after LOD [49]. This finding makes it unlikely that the action of LOD is mediated via inhibin B.

\section{Long-term effects}

Naether and co-workers demonstrated that the effects of LOD lasted for 6 years in most of the cases [37]. In another study, Gjonnaess showed that the endocrine effects of LOD seem to be stable for 18-20 years in 50 women with anovulatory PCOS [50]. However, Elting and co-workers demonstrated that women with PCOS gain regular menstrual cycles as they become older [51]. It is therefore possible that the favourable late endocrine effects demonstrated by Gjonnaess could be the effect of age rather than LOD. More recently and in order to investigate this further we compared the results of long-term follow-up of 116 women with anovulatory PCOS who underwent LOD with that of a comparison group of age matched women $(n=38)$ with PCOS, who did not undergo LOD. We confirmed the 
long-term beneficial endocrine effects of LOD. In addition, we showed that these long term endocrine improvements were produced by LOD rather than the effect of advancing age alone [52]

\section{Clinical outcome}

\section{Short term outcome}

A very rapid response has been reported following LOD in several studies, with ovulation occurring within 2-4 weeks and menstruation within 4-6 weeks in the responders [45]. Recently, in a large randomized controlled trial involving 168 CC-resistant PCOS women, Bayram and co-workers reported ovulation rate of $70 \%$ per cycle and cumulative conception and livebirth rates of $76 \%$ and $64 \%$ respectively following LOD (Table 2) [18].

\section{Long-term outcome}

In a recent long-term follow-up study on 116 women with anovulatory PCOS who underwent LOD, we reported that the improvement in menstrual cycles and reproductive performance seemed to last for many years in about a third of cases [53].

\section{LOD and Assisted Reproduction Treatments}

Recently, there has been a growing body of evidence indicating that LOD prior to Assisted Reproduction Treatments (ART) may offer some benefits such as decreasing the risk of severe OHSS and improving the clinical pregnancy rate in women with previous OHSS or previous IVF cycle cancellation due to risk of OHSS [54-57]. The potential beneficial effect of LOD has been attributed to the postoperative reduction of ovarian blood flow velocity and serum vascular endothelial growth factor (VEGF) concentrations [58-60]. However, 
none of the above studies was properly designed to address this issue adequately and the evidence should therefore be considered preliminary. Further data from adequately designed RCTs are required before adopting pre-ART LOD in clinical practice.

\section{Mechanism of action of LOD}

The mechanism of action of LOD remains largely unexplained. It is likely that LOD exerts its effects via the destruction of androgen producing tissue in the ovary. The resulting decrease in circulating androgen concentrations may result in a fall in oestrone (E1) due to decreased peripheral aromatization of androgens. This fall in E1 may result in decreased positive feedback on LH and decreased negative feedback on FSH at the level of the pituitary. The resulting rise in serum FSH concentrations may result in increased aromatase activity within the follicles. This effect, coupled with a decrease in local androgen concentrations, would convert an androgenic intrafollicular environment to an oestrogenic milieu. This may remove an intraovarian block to follicular maturation, allowing follicular recruitment and development to proceed to subsequent ovulation.

It has also been hypothesised that ovarian injury leads to the production of a number of local factors (e.g. IGF-1) which could affect the ovarian-pituitary feedback mechanism or sensitize ovarian follicles to circulating FSH [61].

\section{Predictors of the outcome of LOD}

We have previously investigated various clinical and biochemical factors that may predict the clinical outcome of LOD in 200 PCOS women [62]. We found that marked obesity $(\mathrm{BMI} \geq 35 \mathrm{~kg} / \mathrm{m} 2$ ), marked hyperandrogenism (testosterone $\geq 4.5 \mathrm{nmo} / \mathrm{l}$ or $\mathrm{FAI} \geq 15$ ) and/or long duration of infertility (>3years) seemed to predict resistance to LOD. We also reported that that high pre-operative LH concentration $(\geq 10 \mathrm{iu} / \mathrm{l})$ in women who ovulated after LOD 
appeared to predict higher probability of pregnancy. Age, the presence or absence of acne, the menstrual pattern, LH:FSH ratio and ovarian volume did not seem to influence the outcome of LOD [62]. In a more recent study, we have found circulating anti Müllerian hormone to negatively correlate with the clinical outcome of LOD. A serum AMH concentration higher than $7.7 \mathrm{ng} / \mathrm{ml}$ (measured by Immunotech, Beckman Coulter UK Ltd, High Wycombe, Buckinghamshire, UK) was found to predict poor outcome in PCOS women undergoing LOD [63].

\section{Complications of laparoscopic ovarian drilling}

Intra-operative complications of LOD are rare and include damage to the utero-ovarian ligament, bleeding from the ovary at the cautery points and thermal injury to the bowel. Post-operatively, the main drawback of LOD is iatrogenic adhesion formation. An incidence of $30-40 \%$ has been reported in various studies [30,32,63-66]. Most studies reported only mild and moderate adhesions which do not seem to affect the pregnancy rate after LOD. Nevertheless, all precautions should be taken to minimize adhesion formation. This can be achieved by minimizing thermal injury to the ovarian surface (as described above), ample irrigation and instillation of crystalloid solution at the end of the procedure [65]. Another theoretical risk associated with LOD is premature ovarian failure possibly due to excessive destruction of the normal ovarian follicles or the inadvertent damage of the ovarian blood supply. In our cohort of 116 patients with PCOS who were followed up for up to nine years after LOD, no case of premature ovarian failure was observed $[52,53]$. This risk can be largely avoided by minimizing the number of punctures made and by delivering the energy away from the ovarian hilum. 


\section{Failure of laparoscopic ovarian surgery}

Women are considered to have failed after LOD if they do not ovulate within 6-8 weeks, if they experience recurrence of the anovulatory status after an initial response or if they fail to conceive despite regular ovulation for 12 months. For anovulatory patients, CC may be restarted. Many studies have demonstrated that LOD renders the ovaries more sensitive to CC $[19,44]$. If the patient is still anovulatory on CC, the treatment options are: (a) gonadotrophin ovarian stimulation; (b) metformin, (c) IVF; or (d) repeat LOD. We have previously reported high success rates after repeat LOD in women who previously responded to their first LOD. On the other hand, repeat LOD was not effective in the previous non-responders [67]

\section{Conclusion}

Laparoscopic ovarian drilling has been widely accepted as the second line of choice for induction of ovulation in CC-resistant PCOS women in preference to gonadotrophin therapy. In addition to its proven efficacy, LOD offers several advantages over gonadotrophins such as avoiding multiple pregnancies and OHSS. Using a monopolar needle applied at right angle to the antimesentric surface of the ovary with penetration of the ovary to a depth of 7-8 $\mathrm{mm}$ at four points with a power setting of $30 \mathrm{~W}$ for 5 seconds per puncture seems to be an optimum approach that maximises effectiveness and safety. PCOS women could expect 50-60\% pregnancy rates during 12 months following LOD. The role of LOD before ART remains to be adequately investigated. In addition to the short term benefits of LOD, about one third women undergoing this surgery will continue to benefit for several years. 
References

1. Michelmore KF, Balen AH, Dunger DB, Vessey MP. Polycystic ovaries and associated clinical and biochemical features in young women. Clin Endocrinol. 1999;51:779-786.

2. Diamanti-Kandarakis E, Kouli CR, Bergiele AT, et al. A survey of the polycystic ovary syndrome in the Greek island of Lesbos: hormonal and metabolic profile. $J$ Clin Endocrinol Metab. 1999;84:4006-4011.

3. Asuncion M, Calvo RM, San Millan JL, Sancho J, Avila S, Escobar-Morreale HF. A prospective study of the prevalence of the polycystic ovary syndrome in unselected Caucasian women from Spain. J Clin Endocrinol Metab. 2000;85:2434-2438.

4. Hull MG. Epidemiology of infertility and polycystic ovarian disease: endocrinological and demographic studies. Gynecol Endocrinol.. 1987;1:235-245.

5. Rotterdam ESHRE/ASRM-Sponsored PCOS Consensus Workshop Group. Revised 2003 consensus on diagnostic criteria and long-term health risks related to polycystic ovary syndrome (PCOS). Hum Reprod. 2004;19:41-47.

6. March WA, Moore VM, Willson KJ, Phillips DI, Norman RJ, Davies MJ. The prevalence of polycystic ovary syndrome in a community sample assessed under contrasting diagnostic criteria. Hum Reprod. 2010;25:544-551.

7. Yildiz BO, Bozdag G, Yapici Z, Esinler I, Yarali H. Prevalence, phenotype and cardiometabolic risk of polycystic ovary syndrome under different diagnostic criteria. Hum Reprod. 2012;27:3067-3073.

8. Thessaloniki ESHRE/ASRM-Sponsored PCOS Consensus Workshop Group. Consensus on infertility treatment related to polycystic ovary syndrome. Hum Reprod. 2008;23:462-477.

9. Stein IF, Leventhal ML. Amenorrhoea associated with bilateral polycystic ovaries. Am J Obstet Gynaecol. 1935;29:181-191.

10. Greenblatt RB. Chemical induction of ovulation. Fertil Steril. 1961;12:402-404.

11. Buttram VC, Vaquero C. Post-ovarian wedge resection adhesive disease. Fertil Steril. 1975; 26: 874-876.

12. Palmer R, de Brux J. Résulats histologiques, biochemiques et therapeutiques 
obtenus ches les femmes don't les ovaries avaient été diagnostiqués Stein-Leventhal à la coelioscpie. Bulletin Federation Societes de Gynecologie et Obstetrique de Langue Française. 1967;19:405-412.

13. Gjonnaess H. Polycystic ovarian syndrome treated by ovarian electrocautery through the laparoscope. Fertil Steril. 1984; 41:20 - 25.

14. Armar NA, McGarrigle HHG, Honour J, et al. Laparoscopic ovarian diathermy in the management of anovulatory infertility in women with polycystic ovaries: endocrine changes and clinical outcome. Fertil Steril. 1990; 53: 45-9.

15. Huber J, Hosmann J, Spona J. Polycystic ovarian syndrome treated by laser through the laparoscope [letter]. Lancet. 1988; 2: 215.

16. Moll E, Bossuyt PM, Korevaar JC, Lambalk CB, van der Veen F. Effect of clomifene citrate plus metformin and clomifene citrate plus placebo on induction of ovulation in women with newly diagnosed polycystic ovary syndrome: randomised double blind clinical trial. BMJ. 2006; 24:1485.

17. Legro RS, Barnhart HX, Schlaff WD et al. Clomiphene, metformin, or both for infertility in the polycystic ovary syndrome. $N$ Engl $\mathrm{J} \mathrm{Med}$. 2007;356: 551-566.

18. Bayram N, van Wely M, Kaaijk EM, Bossuyt PM, van der Veen F. Using an electrocautery strategy or recombinant follicle stimulating hormone to induce ovulation in polycystic ovary syndrome: randomised controlled trial. BMJ. 2004;328:192-.

19. Farquhar C, Lilford RJ, Marjoribanks J, Vandekerckhove P. Laparoscopic "drilling" by diathermy or laser for ovulation induction in anovulatory polycystic ovary syndrome. Cochrane Database Syst Rev. 2005;20:CD001122.

20. Farquhar CM. An economic evaluation of laparoscopic ovarian diathermy versus gonadotrophin therapy for women with clomiphene citrate-resistant polycystic ovarian syndrome. Curr Opin Obstet Gynecol. 2005;17:347-353.

21. Nahuis MJ, Oude Lohuis E, Kose N, Bayram N, Hompes P, Oosterhuis GJ, Kaaijk EM, Cohlen BJ, Bossuyt PP, van der Veen F, Mol BW, van Wely M. Long-term follow-up of laparoscopic electrocautery of the ovaries versus ovulation induction 
with recombinant FSH in clomiphene citrate-resistant women with polycystic ovary syndrome: an economic evaluation. Hum Reprod. 2012;27:3577-3582.

22. Amer S, Li TC, Emarh M. Metwally M, Ledger WL. Randomized controlled trial comparing laparoscopic ovarian diathermy with clomifene citrate as a first line method of ovulation induction in women with polycystic ovarian syndrome. Hum Reprod. 2009;24:219-225

23. Weise HC, Naether O, Fischer R, Berger-Bispink S, Delfs T. Behand-lungebnisse mit der oberflachenkuater-isierung polyzystischer ovarian bei Sterilitatspatientinnen. Geburtshilfe Frauenheilkd. 1991;51:920-924.

24. Naether OGJ, Fischer R, Weise HC, Geiger-Kotzler L, Delfs T, Rudolf K. Laparoscopic electrocoagulation of the ovarian surface in infertile patients with polycystic ovarian disease. Fertil Steril. 1993; 60:88-94.

25. Amer SA, Li TC, Cooke ID. Laparoscopic ovarian diathermy in women with polycystic ovarian syndrome: a retrospective study on the influence of the amount of energy used on the outcome. Hum Reprod. 2002;17:1046-1051.

26. Amer S, Li TC, Cooke ID. A prospective dose finding study of the amount of energy required for laparoscopic ovarian diathermy in women with polycystic ovarian syndrome. Hum Reprod. 2003;18:1693-1698.

27. Felemban A. Tan SL. Tulandi T. Laparoscopic treatment of polycystic ovaries with insulated needle cautery: a reappraisal. Fertil Steril. 2000;73,2:266-269.

28. Greenblatt E, Casper RF. Endocrine changes after laparoscopic ovarian cautery in polycystic ovarian syndrome. Am J Obstet Gynaecol. 1987;156:279-285.

29. Lemieux S, Lewis GF, Ben-Chetrit A, Steiner G, Greenblatt EM. Correction of hyperandrogenemia by laparoscopic ovarian cautery in women with polycystic ovarian syndrome is not accompanied by improved insulin sensitivity or lipidlipoprotein levels. J Clin Endocrinol Metab. 1999;84:4278-4282.

30. Pelosi MA, Pelosi MA. Laparoscopic electrosurgical furrowing technique for the treatment of polycystic ovaries. J Am Assoc Gynaecol Laparosc. 1996;4:57-62. 
31. Merchant RN. Treatment of polycystic ovary disease with laparoscopic low-watt bipolar electrocoagulation of the ovaries. J Am Assoc Gynaecol Laparosc. 1996;3:503-508.

32. Gurgan T, Kisnisci H, Yarali H, Develioglu O, Zeyneloglu H, Aksu T. Evaluation of adhesion formation after laparoscopic treatment of polycystic ovarian disease. Fertil Steril. 1991;56:1176- 1178.

33. Keckstein G, Rossmanith W, Spatzier K, Schneider V, Borchers K, Steiner R. The effect of laparoscopic treatment of polycystic ovarian disease by $\mathrm{CO}_{2}$ - laser or Nd:YAG laser. Surg Endosc. 1990;4:103-107.

34. Keckstein J. Laparoscopic treatment of polycystic ovarian syndrome. Baillieres Clin Obstet Gynaecol. 1989;3:563-581.

35. Kojima E, Yanagibori A, Otaka K, Hirakawa S. Ovarian wedge resection with contact Nd:YAG laser irradiation used laparoscopically. $J$ Reprod Med. 1989;34:444-446.

36. Li TC, Saravelos H, Chow MS, Chisabingo R, Cooke ID. Factors affecting the outcome of laparoscopic ovarian drilling for polycystic ovarian syndrome in women with anovulatory infertility. Br J Obstet Gynaecol. 1998;105:338-344.

37. Naether OGJ, Baukloh V, Fischer R, Kowalczyk T. Long-term follow-up in 206 infertility patients with polycystic ovarian syndrome after laparoscopic electrocautery of the ovarian surface. Hum Reprod. 1994;9:2342-2349.

38. Mio Y, Toda T, Tanikawa M, Terado H, Harada T, Terakawa N. Transvaginal ultrasound-guided follicular aspiration in the management of anovulatory infertility associated with polycystic ovaries. Fertil Steril. 1991;56:1060-1065.

39. Syritsa A. Transvaginal ultrasound-guided electrocautery of the ovaries in infertile patients with polycystic ovarian disease. Int J Gynaecol Obstet. 1998;63:293-294.

40. Zhu W, Li X, Chen X, Lin Z, Zhang L. Ovarian interstitial YAG-laser: an effective new method to manage anovulation in women with polycystic ovary syndrome. Am J Obstet Gynecol. 2006;195:458-463. 
41. Fernandez H, Watrelot A, Alby JD, et al. Fertility after ovarian drilling by transvaginal fertiloscopy for treatment of polycystic ovary syndrome. J Am Assoc Gynecol Laparosc. 2004;11:374-378.

42. Ramzy AM, Al-Inany H, Aboulfoutouh I, Sataar M, Idrees OA, Shehata MH. Ultrasonographic guided ovarian stroma hydrocoagulation for ovarian stimulation in polycystic ovary syndrome. Acta Obstet Gynecol Scand. 2001;80:1046-1050.

43. Chiesa-Montadou S, Rongieres C, Garbin O, Nisand I. [About two complications of ovarian drilling by fertiloscopy] Gynecol Obstet Fertil. 2003;31:844- 846.

44. Kovacs G, Buckler H, Bangah M, et al. Treatment of anovulation due to polycystic ovarian syndrome by laparoscopic ovarian electrocautery. $\mathrm{Br} J$ Obstet Gynaecol. 1991;98:30- 35.

45. Liguori G, Tolino A, Moccia G, Scognamiglio G, Nappi C. Laparoscopic ovarian treatment in infertile patients with polycystic ovarian syndrome (PCOS): endocrine changes and clinical outcome. Gynaecol Endocrin. 1996;10:257- 264.

46. Aakvaag A, Gjonnaess H. Hormonal response to electrocautery of the ovary in patients with polycystic ovarian disease. Br J Obstet Gynaecol. 1985;92:1258- 1264.

47. Gjonnaess H, Norman N. Endocrine effects of the ovarian electrocautery in patients with polycystic ovarian disease. Br J Obstet Gynaecol. 1987;94:779-783.

48. Abdel-Gadir A, Mowafi RS, Alnaser HMI, Alrashid AH, Alonezi OM, Shaw RW. Ovarian electrocautery versus human gonadotrophins and pure follicle stimulating hormone therapy in the treatment of patients with polycystic ovarian disease. Clin Endocrinol (Oxf). 1990;33:585-592.

49. Amer S, Laird S, Ledger WL, Li TC. Effect of laparoscopic ovarian diathermy on circulating inhibin B in women with anovulatory polycystic ovarian syndrome. Hum Reprod. 2007;22:389-394.

50. Gjonnaess H. Late endocrine effects of Ovarian electrocautery in of women with polycystic ovary Syndrome. Fertil Steril. 1998;69:697-701.

51. Elting MW, Korsen TJ M, Rekers-Mombarg LTM, Schoemaker J. Women with polycystic ovary syndrome gain regular menstrual cycles when ageing. Hum Reprod. 2000;15:24-28. 
52. Amer S, Li TC, Banu Z, Cooke ID. Long term follow up of patients with polycystic ovarian syndrome after laparoscopic ovarian drilling: endocrine and ultrasonographic outcomes. Hum Reprod. 2002;17:2851-2857.

53. Amer S, Li TC, Gopalan V, Ledger WL, Cooke ID. Long term follow up of patients with polycystic ovarian syndrome after laparoscopic ovarian drilling: clinical outcome. Hum Reprod. 2002;17: 2035-1042.

54. Fukaya T, Murakami T, Tamura M, Watanabe T, Terada Y, Yajima A. Laser vaporization of the ovarian surface in polycystic ovary disease results in reduced ovarian hyperstimulation and improved pregnancy rates. Am J Obstet Gynecol. 1995;173:119-125.

55. Colacurci N, Zullo F, De Franciscis P, Mollo A, De Placido G. In vitro fertilization following laparoscopic ovarian diathermy in patients with polycystic ovarian syndrome. Acta Obstet Gynecol Scand. 1997;76:555-558.

56. Tozer AJ, Al-Shawaf T, Zosmer A, Hussain S, Wilson C, Lower AM, Grudzinskas JG. laparoscopic ovarian diathermy affect the outcome of IVF embryo transfer in women with polycystic ovarian syndrome? A retrospective comparative study. Hum Reprod. 2001; 16:91-95.

57. Rimington MR, Walker SM, Shaw RW. The use of laparoscopic ovarian electrocautery in preventing cancellation of in vitro fertilization treatment cycles due to risk of ovarian hyperstimulation syndrome in women with polycystic ovaries. Hum Reprod. 1997;12:1443-1447.

58. Amin AF, Abdel-Aal DE, Darwish AM, Mbeki AR. Evaluation of the impact of laparoscopic ovarian drilling on Doppler indices of ovarian stoma blood flow, serum vascular endothelial growth factor, and insulin-like growth factor-1 in women with polycystic ovary syndrome. Fertil Steril. 2003;79:938-942.

59. Parsanezhad ME, Bagheri MH, Alborzi S, Schmidt EH. Ovarian stromal blood flow changes after laparoscopic ovarian cauterization in women with polycystic ovary syndrome. Hum Reprod. 2003;18:1432-1437.

60. El Behery MM, Diab AE, Mowafy H, Ebrahiem MA, Shehata AE. Effect of laparoscopic ovarian drilling on vascular endothelial growth factor and ovarian stromal blood flow using 3-dimensional power Doppler. Int J Gynaecol Obstet. 2011;112:119-121 
61. Rossmanith WG, Keckstein J, Spatzier K, Lauritzen C. The impact of ovarian laser surgery on the gonadotrophin secretion in women with polycystic ovarian disease. Clin Endocrinol (Oxf). 1991;34:223-230.

62. Amer S, Li TC, Ledger WL. Ovulation induction using laparoscopic ovarian drilling in women with polycystic ovarian syndrome: Predictors of success. Hum Reprod. 2004;19:1719-1724.

63. Amer S, Li TC, Ledger WL. The value of measuring anti-Müllerian hormone in women with anovulatory polycystic ovary syndrome undergoing laparoscopic ovarian diathermy. Hum Reprod. 2009;24:2760-2766.

64. Greenblatt EM, Casper RF. Adhesion formation after laparoscopic ovarian cautery for polycystic ovarian syndrome: lack of correlation with pregnancy rate. Fertil Steril. 1993;60:766-770.

65. Naether OGJ. Significant reduction of adnexal adhesions following laparoscopic electrocautery of the ovarian surface (LEOS) by lavage and artificial ascites. Gynaecol Endosc. 1995;4:17-19.

66. Saravelos H, Li TC. Post-operative adhesions after laparoscopic electrosurgical treatment for polycystic ovarian syndrome with the application of Interceed to one ovary: a prospective randomized controlled study. Hum Reprod. 1996;11:992-997.

67. Amer S, Li TC, Cooke ID. Repeated laparoscopic ovarian diathermy is effective in women with anovulatory infertility due to polycystic ovarian syndrome. Fertil Steril. 2003;79:1211-1215. 
Table 1: History of treatment of anovulatory PCOS

\begin{tabular}{ll}
\hline Date & Treatment of anovulatory infertility in PCOS \\
\hline 1930 & Bilateral ovarian wedge resection $\quad$ (Stein \& Leventhal, 1935) \\
1961 & Clomiphene citrate (Greenblatt, 1961) \\
1967 & Laparoscopic ovarian biopsies (Palmer \& de Brux, 1967) \\
1978 & Laparoscopic ovarian diathermy (Gjonnaess, 1984) \\
1990 & Laparoscopic ovarian drilling [Laser] (Huber et al, 1988) \\
\hline
\end{tabular}

Table 2: LOD vs. rFSH in CC-resistant PCOS women (RCT by Bayram and co-workers [18])

\begin{tabular}{lcc}
\hline & LOD $(n=83)$ & rFSH $(n=85)$ \\
\hline Ovulation (per cycles) & $70 \%$ & $69 \%$ \\
Conception at 12/12 & $76 \%$ & $75 \%$ \\
Multiple pregnancies & $1(>2 \%)$ & $9(14 \%)$ \\
Miscarriage rate & $11 \%$ & $11 \%$ \\
Livebirth rate & $64 \%$ & $60 \%$ \\
\hline
\end{tabular}

NB: Women who remained anovulatory after LOD were given CC $(n=45)$ and those who did not respond to $\mathrm{CC}(\mathrm{n}=23)$ received $\mathrm{rFSH}(\mathrm{n}=23)$. 
Table 3: LOD vs. rFSH rFSH in CC-resistant PCOS women (Cochrane systematic review by Farquhar and co-workers [19])

OR $(95 \% \mathrm{CI})$

Cumulative pregnancy

Livebirth

Multiple pregnancy

Miscarriage rates
$1.04(0.74,1.99)$

$1.08(0.67,1.75)$

$0.13(0.03,0.59)$

$0.81(0.36,1.86)$

Table 4: Advantages and disadvantages of LOD

\section{A. Advantages}

1. At least as effective as gonadotrophin treatment

2. Less Costly

3. Avoids intensive, inconvenient and complex monitoring

4. Single treatment produces repeated ovulatory cycles and potentially repeated pregnancies

5. Avoids OHSS

6. No increase in muliple pregnanccies

B. Disadvantages:

1. The need for surgery under general anaesthetic

2. Iatrogenic adhesion formation

3. Theoretical risk of premature ovarian failure 
Table 5: Techniques of LOD using electrocautery

1. Three-Puncture technique

2. Utero-ovarian ligament is grasped with a pair of atraumatic forceps.

3. The ovary is lifted up away from the bowel and stabilized.

4. A specially designed monopolar electrocautery needle probe is used.

5. The needle applied at right angle to the anti-mesenteric surface of the ovary.

6. The needle should be away from ovarian hilum and the Fallopian tube.

7. Power is set at 30 watt (coagulating)

8. The full length of the needle is pushed into the capsule to a depth of $6-8 \mathrm{~mm}$

9. Electricity is activated for 5 seconds.

10. Four punctures are made in each ovary.

11. The ovary is cooled with saline at the end of the drilling procedure.

12. A crystalloid solution is instilled at the end of the procedure. 
Figure 1: management options for anovulatory infertility associated with PCOS

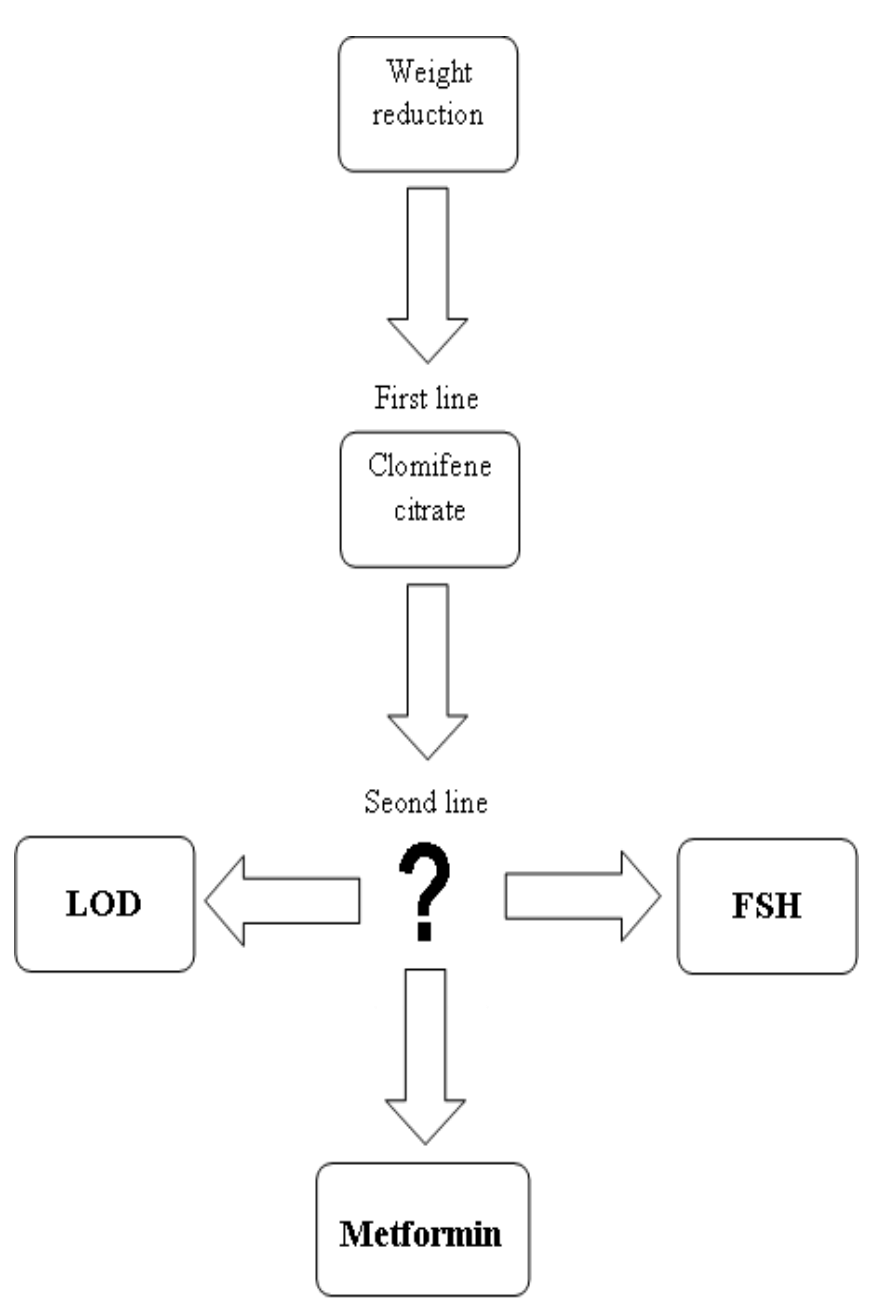

Weight reduction should be considered before any medical induction of ovulation in all overweight/obese PCOS women

Clomifene citrate $(\mathrm{CC})$ is the standard first-line medical ovulation induction in non-obese PCOS women

The second line treatment after CC-resistance/failure is still uncertain with competition between LOD, gonadotrophin and metformin to be the preferred choice. 
Figure 2: Laparoscopic ovarian drilling with monopolar electrocautery

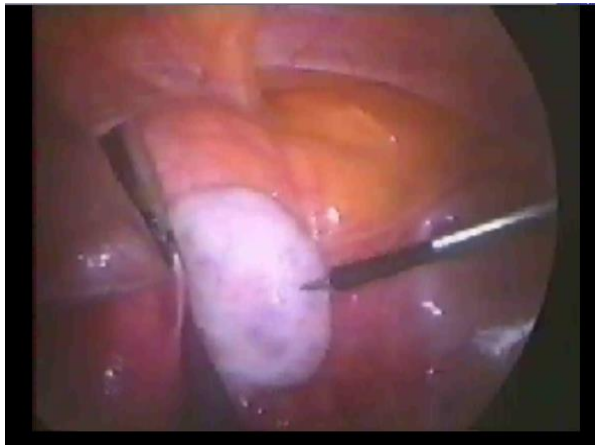

a. The utero-ovarian ligament is grasped with atraumatic grasping forceps and the ovary is lifted up away from the bowel. With the ovary stabilized in position, the needle is applied to the anti-mesenteric surface at right angle.

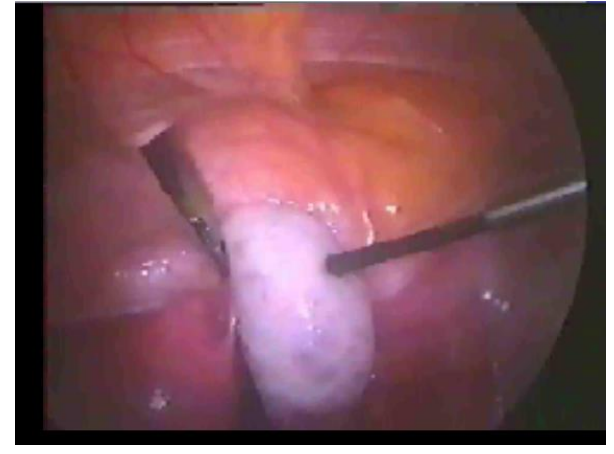

b. The full length of the needle is pushed into the ovarian capsule and electricity is activated for 5 seconds. This is repeated at 4 separate points.

Figure 3: Laparoscopic ovarian drilling with argon laser

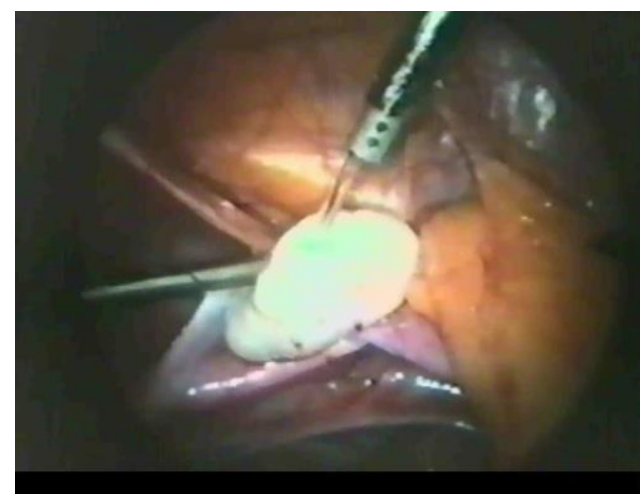

The argon laser fibre is introduced through a suction irrigation probe and is applied to the anti-mesenteric surface of the ovary. The fibre is pushed into the ovarian capsule and laser is activated for 1 second with power setting at $6-16 \mathrm{w}$. Twenty to forty punctures are usually made. 